\title{
Repercussões Psicológicas do Transplante de Medula Óssea no Doador Relacionado
}

Psychological repercussions of bone marrow transplants on related donors

Érika Arantes de Oliveira, Manoel Antônio dos Santos, Ana Paula Mastropietro \& Júlio César Voltarelli

Universidade de São Paulo

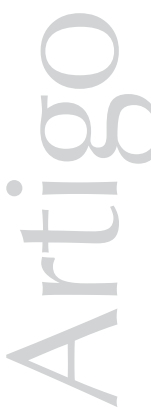




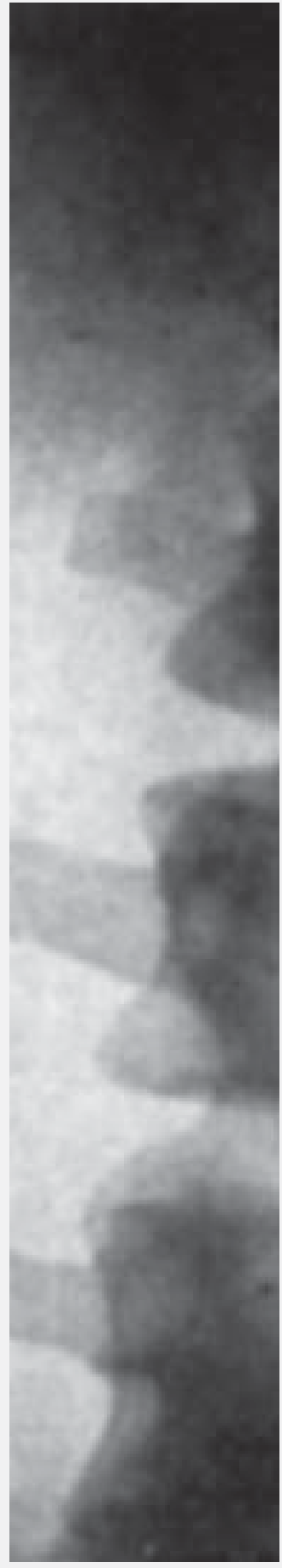

Resumo: O desenvolvimento do transplante de medula óssea (TMO), nas últimas décadas, permitiu o tratamento de doenças que antes eram invariavelmente fatais. Dentre os tipos de transplante realizados, o alogênico exige a participação ativa de um membro familiar, em geral, o irmão, que arca com o encargo da doação. O objetivo do presente estudo é analisar as repercussões psicológicas dessa doação nos doadores relacionados. A amostra foi composta por dez doadores, vinculados à Unidade de TMO do HCFMRP-USP, avaliados antes e após a doação. Os instrumentos utilizados foram: roteiro de entrevista, escalas e técnicas projetivas. Os resultados demonstraram que o nível de ansiedade dos sujeitos se encontrava dentro do esperado, porém foram constatados sintomas de estresse. Afirmaram terem ficado ansiosos e relataram dor no momento pós-doação, mas acreditam que esta foi mais fácil do que imaginaram. Finalmente, em relação aos dados das técnicas projetivas, constatou-se uma alta suscetibilidade emocional, indícios de sugestionabilidade e dependência.

Palavras-chave: transplante de medula óssea, estresse, ansiedade, doador relacionado.

Abstract: The development of bone marrow transplantation (BMT) in the last decades allowed the treatment of diseases which were invariably deadly beforehand. Among the types of transplantations recently accomplished, the allogenic demands the active participation of a member of the family, usually the brother, who donates the bone marrow. The aim of the present study is to analyze the psychological repercussions of this donation in the related donors. The sample was composed of ten subjects, linked to the Unit of Bone Marrow Transplantation of the HCFMRP-USP. The applied instruments were: interview script, scales e projective techniques. The results demonstrate that the level of anxiety of the subjects is the expected, but stress symptoms also appear. The individuals stated they felt anxious, painful and worried the day after the donation, but they believe that the donation was much easier than they had expected. Finally, in relation to the data of the projective techniques, higher levels of emotional susceptibility, sugestionability and dependence were detected.

Key words: bone marrow transplantation, stress, anxiety, related donor. 
O diagnóstico inaugura um momento de crise, mas um novo conflito logo vai se instalar, gerando inquietação e insegurança: realizar ou não um procedimento de alta complexidade como o TMO, com enormes riscos associados?
As primeiras intervenções científicas do transplante de medula óssea (TMO) foram realizadas em camundongos e, posteriormente, em cães (Andrykowski, 1994). O sucesso dessa modalidade terapêutica só se consolidou em 1968, sendo que, após essa data, tornou-se um dos mais promissores tratamentos para uma série de graves enfermidades. Atualmente, o TMO vem se constituindo em alternativa eficaz de tratamento para enfermidades potencialmente fatais (Thomas, 2000), cujos diagnósticos geram impacto psicológico para o paciente e para toda a sua unidade familiar (Riveral, 1997).

As famílias, nesse momento, enfrentam a perda da vida "normal", tal como era antes do diagnóstico, sendo obrigadas a elaborar o luto pela perda da vida cotidiana que tinham enquanto unidade familiar antes da doença, além do luto pelos sonhos e esperança no futuro. Aliado aos eventos estressores, os familiares se vêem obrigados a encarar a destruição do mito familiar de que as doenças fatais só acontecem com os outros (Rolland, 1998).

O diagnóstico inaugura um momento de crise, mas um novo conflito logo vai se instalar, gerando inquietação e insegurança: realizar ou não um procedimento de alta complexidade como o TMO, com enormes riscos associados? Esse questionamento se dá, principalmente, em virtude das peculiaridades dessa terapêutica - o transplante é visto como um tratamento-salvador e, ao mesmo tempo, como um tratamento-ameaçador (Copper, Powell, 1998). Nessa última categoria, é preciso considerar que o transplante implica, verdadeiramente, riscos severos para o paciente, inclusive perda da integridade física e, acima de tudo, a possibilidade de insucesso e, por conseguinte, perda da própria vida.

Paralelamente, essas ameaças afetam também os familiares, que se vêem confrontados com a iminência de perder um ente querido. Por outro lado, o transplante também é uma possibilidade bastante palpável de salvação, muitas vezes considerada como o único meio de se alcançar a cura. É justamente essa esperança de cura que impulsiona a resolução pelo TMO, que passa a ser visto como a única chance de redenção que resta, uma espécie de luz no fim do túnel (Prows; Mccain, 1997).

Uma vez feita a opção pelo transplante, iniciase a busca pelo doador de medula, que pode ser proveniente do núcleo familiar (doador relacionado) ou disponibilizado mediante a doação de voluntários (doadores não relacionados). Em geral, a doação é realizada por algum familiar, freqüentemente um irmão, escolhido por meio de um exame prévio para a detecção da compatibilidade (Thomas, 2000).

O doador é internado na véspera do procedimento, que requer permanência em jejum de pelo menos oito horas, e sua hospitalização dura cerca de dois a três dias. Na maioria dos casos, para a realização da aspiração da medula, o doador recebe anestesia geral (Williams, McCarthy, 1998). A coleta é feita por meio do acesso bilateral das cristas ilíacas posteriores, através de agulhas calibrosas, que realizam inúmeras punções no osso ilíaco (Demko, 1998). Embora o volume total retirado da medula seja variável, em média, o valor aproxima-se de um litro. Depois de concluído o procedimento, o doador necessitará da autotransfusão de sangue. Receberá alta no dia seguinte à doação, com 
receita de sulfato ferroso para a reposição do ferro espoliado na doação, com recuperacão prevista para aproximadamente 20 dias após o procedimento (Stroncek, Holland, Bartch, 1993).

Apesar de bem estabelecidos os aspectos técnicos da doação de medula óssea, o doador tem sido foco de escassas investigações empíricas (Andrykowski, 1994). A esse respeito, Lesko (1990) e, posteriormente, Cristopher (2000), lamentam essa pouca atenção da literatura, pois acreditam que o doador possa vir desenvolver problemas psicológicos em decorrência da doação. Da mesma forma, Buckner, Petersen e Bolonesi (1994) afirmam que, na doação relacionada, o que motiva o doador é o fato de o indivíduo ser colocado, potencialmente, como o salvador da vida de um membro familiar, sendo muito difícil a recusa da doação. Essa responsabilidade delegada pela família para a sobrevivência do irmão torna-se, muitas vezes, opressiva, o que pode, segundo Shama (1998), desencadear um nível significativo de angústia.

A angústia vivenciada pelos doadores relacionados motivou um estudo realizado por Chang et al. (1998), objetivando verificar se eles experimentavam mais angústias do que os não relacionados. Participaram do estudo 77 doadores (41 não relacionados e 36 relacionados). Os resultados encontrados indicaram que, no período pré-doação, os doadores relacionados endossam mais itens do inventário de depressão de Beck - BDI, e, após a doação, descreviam uma sensação de dor maior do que os não relacionados, diferença essa que não pôde ser justificada por questões referentes à técnica utilizada no procedimento. Tais resultados sustentam a argumentação de que o processo de doação gera angústia nos doadores relacionados, além de desvelar a importância de abordar os fatores psicológicos no processo de doação de medula óssea.

Chang et al. (2003) realizaram uma outra pesquisa visando a identificar as mudanças percebidas depois da doação por 23 doadores relacionados. Analisando o inventário de depressão de Beck - BDI, constataram que, aproximadamente seis meses depois da doação, os doadores cujos receptores faleceram apresentavam maior índice de sintomas de depressão do que aqueles cujos irmãos sobreviveram. Esse resultado mostra que a doação não se restringe somente a um procedimento técnico, mas que as implicações psicológicas vão além do ato de doar em si e o estado emocional do doador depende da sobrevida do paciente.

Em um estudo anterior a esse, Wolcoot et al. (1986) já haviam demonstrado essa correlação entre a sobrevida e o estado de saúde do paciente e a qualidade de vida do doador, e sugeriram que a depreciação da qualidade de vida do receptor - e não somente a sua morte - causava impacto adverso na vida do doador relacionado. Constata-se, desse modo, que as condições físicas do receptor estão intimamente associadas às reações emocionais do doador (Andrykowski, 1994).

De acordo com a literatura consultada, muito restrita em relação aos doadores relacionados de medula óssea, percebe-se que a doação acarreta implicações psicológicas para os doadores: antes da doação, na forma de angústia (Fortaneir et al., 2002; Bredesonet al., 2004); imediatamente após a doação, por meio da influência dos fatores psicológicos na 
experiência do procedimento (Chang et al., 1998), e, decorridos anos de sua realização, pelas modificações observadas na sua qualidade de vida, que se torna diretamente dependente da qualidade de vida do irmãoreceptor (Cristopher, 2000).

Considerando esses resultados, o presente estudo tem por objetivo analisar as repercussões psicológicas da doação nos doadores relacionados de medula óssea, antes da doação e imediatamente depois, com a avaliação do nível de ansiedade e estresse, análise do relato sobre a vivência de ser doador e o conhecimento de alguns aspectos da personalidade desses doadores relacionados.

\section{Método}

O presente trabalho pode ser caracterizado como uma pesquisa clínica, uma vez que o problema investigado emerge da experiência prática do pesquisador (Diers, 1978; Brewer; Hunter, 1989). Trata-se de um estudo qualitativo exploratório com recorte longitudinal, no qual se pretende avaliar as repercussões psicológicas de doadores de transplante de medula óssea.

Participantes

Participaram do estudo dez doadores de medula óssea (cinco homens e cinco mulheres), da Unidade de Transplante de Medula Óssea (UTMO), todos irmãos de pacientes submetidos ao TMO no Hospital das Clínicas da Faculdade de Medicina de Ribeirão Preto. Foram incluídos todos os doadores, com idade superior a 18 anos, que efetuaram a doação da medula no primeiro semestre do ano 2000.
A idade dos participantes variou de 18 a 42 anos, sendo a média 28,9 anos. A metade dos participantes era casada, dentre os quais quatro eram mulheres e um homem; o grau de instrução foi bastante variado (cinco haviam completado o ensino fundamental, quatro o ensino médio, e um era analfabeto).

Instrumentos/procedimentos

A coleta de dados ocorreu após a aprovação do projeto pelo Comitê de Ética em Pesquisa do HCFMRP-USP (Processo no 7617/99), e foi dividida em dois momentos: quando o doador selecionado chega ao serviço e imediatamente após a doação. O primeiro contato com o doador foi subdividido em duas sessões, sendo aplicados entrevistas, inventários e técnicas projetivas; posteriormente à doação, foi novamente aplicado um roteiro breve de entrevista.

Optou-se pela combinação de diversos instrumentos (inventários, entrevistas, técnicas projetivas), com o propósito de se obter uma compreensão mais ampla dos aspectos psicológicos dos doadores de medula óssea. Essa combinação de instrumentos foi utilizada por Almeida, Loureiro e Voltarelli (1998) com o objetivo de avaliar o ajustamento psicológico de pacientes submetidos ao TMO. Esses autores apontam a escassa utilização de técnicas de exame psicológico em nosso meio, em especial das técnicas projetivas, e argumentam que é necessário incrementar seu uso no contexto da saúde (Contel et al., 2000).

A entrevista, de acordo com Triviños (1992), é um dos principais meios de que dispõe o investigador para a coleta de dados, uma vez que valoriza a presença consciente e atuante 
do investigador e oferece a possibilidade de o informante alcançar a liberdade e a espontaneidade em suas respostas. Na etapa pré-doação, o roteiro de entrevista visava a coletar informações sobre a história pessoal, história familiar, condição de vida atual, percepção acerca do adoecimento do irmão, do transplante de medula óssea e da doação da medula bem como dos projetos futuros dos doadores. Na pós-doação, a entrevista teve o propósito de investigar a percepção dos doadores acerca do processo de doação: lembranças do acontecido no momento imediatamente anterior à doação, da aspiração da medula e do momento imediatamente posterior a esta.

Com o intuito de avaliar os aspectos afetivoemocionais dos doadores, utilizou-se também o teste das pirâmides coloridas, de Pfister (Villemor Amaral, 1978). Trata-se de uma técnica não-verbal e de formato lúdico, o que a torna apropriada para sujeitos com baixo nível de escolaridade. Embora existam diferenças metodológicas entre autores, todos concordam no que diz respeito à possibilidade de se obterem ricas informações sobre a vivência afetiva e o dinamismo psíquico bem como sobre a situação atual e a condição afetiva da personalidade dos indivíduos submetidos à técnica. De acordo com Marques (1988), de todas as técnicas projetivas em geral, o Pfister pode ser considerado um dos testes de personalidade que maior simplicidade apresenta em relação à técnica de aplicação. As instruções dadas são facilmente compreendidas pelo sujeito, mesmo quando este se encontra sob forte perturbação afetivoemocional. Isso ocorre porque o estímulo cor favorece sensivelmente a resposta do sujeito à solicitação do instrumento, o que nem sempre ocorre com outras técnicas de avaliação de personalidade.

Ainda com a intenção de desvelar os conteúdos e processos emocionais inconscientes e conscientes referentes às relações dos participantes com seus objetos internos e externos pertinentes ao mundo familiar, foi utilizado o desenho da família DF (Corman,1961/1994). Trata-se de um instrumento gráfico projetivo indicado como recurso auxiliar na investigação clínica da personalidade de crianças e adolescentes. Parte do pressuposto de que o sujeito projeta, em sua representação gráfica da família, o modo como vivencia a relação com seus pais e demais membros familiares que constituíram figuras significativas em suas vidas (objetos internos) bem como as fantasias inconscientes, conflitos, ansiedades e impulsos ligados à satisfação de suas necessidades básicas. Obtém-se, assim, uma apreciação do modo como se deu o processo de interiorização dos objetos e das relações objetais bem como da qualidade desses relacionamentos primários, fundamentais na estruturação da personalidade e na relação estabelecida como o ambiente social. Na aplicação do DF, foi solicitada ao sujeito a realização de um desenho, mediante a instrução verbal "desenhe uma família"; após o término da tarefa gráfica, procedeu-se à etapa do inquérito, na qual o aplicador obteve esclarecimentos acerca da produção do participante. Tal inquérito foi constituído pelas seguintes questões: 1) Quem você desenhou? 2) Qual a idade deles? 3) Onde eles estão? 4) O que eles estão sentindo? 5) Há alguém nessa família que não está bem? 6) Há alguém doente nessa família? 7) Do que cada um mais gosta? 8) De que cada um menos gosta? 9) $\mathrm{O}$ que vai acontecer com eles? 
"Eu, para falar bem a verdade, não era muito chegado nele, às vezes até tenho raiva dele, mas na hora que falaram que era um câncer que ele tinha, eu não acreditei... a gente pensa que isso só acontece com os outros, com a família da gente, não."

doador 6, feminino, 31 anos, casada
Visando a identificar a sintomatologia de estresse e o tipo de sintoma predominante (psicológico ou somático) bem como a fase de estresse em que se encontra (alerta, resistência, quase-exaustão ou exaustão) (Lipp; Guevara, 1984), foi aplicado o inventário de sintoma de stress para adultos, de Lipp - ISSL (LIPP, 2000). Com o objetivo de avaliar o nível de ansiedade dos doadores frente à necessidade de doação da medula óssea, aplicou-se o inventário de ansiedade traço-estado - IDATE (Spielberger; Gorsuch; Lushene, 1979), adaptado e validado para o contexto brasileiro por Biaggio, Natalício e Spielberger (1977). Esse inventário foi elaborado com a finalidade de avaliar dois conceitos distintos de ansiedade: estado de ansiedade (A-estado: nível de ansiedade transitória) e traço de ansiedade (A-traço: nível de ansiedade relativamente estável).

Análise dos dados

O trabalho de levantamento dos resultados das técnicas aplicadas foi realizado por dois juízes (psicólogos com experiência em avaliação psicológica) de forma independente e concomitante à sua coleta. Os protocolos do IDATE e ISSL foram cotados segundo as recomendações específicas disponíveis na literatura; no teste das pirâmides coloridas de Pfister, foram utilizados os dados normativos brasileiros propostos por Villemor Amaral (1978) para a idade adulta; a análise do DF foi realizada segundo o modelo de avaliação proposto por Lourenção van Kolk (1984), Santos (1997) e Cunha (2000).

Em relação às entrevistas, o material audiogravado foi transcrito na íntegra e analisado mediante a abordagem qualitativa de análise de conteúdo temática (Bogdan;
Biklen,1991; Triviños, 1992; Minayo, 1994).

\section{Resultados}

Os resultados das técnicas serão apresentados separadamente em uma primeira etapa para, em seguida serem integrados, culminando com uma análise compreensiva a ser sistematizada a título de discussão. Nos resultados gerais, trabalhou-se com as concordâncias e discordâncias identificadas no conteúdo das entrevistas e com as médias, ou respostas mais salientes obtidas nos demais instrumentos. $\mathrm{O}$ intuito dessa análise é descrever o perfil do grupo formado pelos doadores relacionados, no que tange aos itens mensurados pelos instrumentos.

Entrevista pré-doação

De acordo com os dados obtidos nas entrevistas, vários eventos estressores acometeram simultaneamente o doador de medula óssea: o adoecimento do irmão, a decisão de realizar o transplante e o encargo de ser o doador da medula.

A reação mais comum ao diagnóstico foi o "susto" e o "desespero". A maioria dos doadores não havia notado nada de errado com a saúde do irmão, e, no momento em que foram notificados da enfermidade, mesmo aqueles irmãos afetivamente mais afastados ou que haviam tido problemas de relacionamento interpessoal com o paciente viram-se mobilizados afetivamente pelo diagnóstico do irmão, como ilustrado na fala que se segue.

“Eu, para falar bem a verdade, não era muito chegado nele, às vezes até tenho raiva dele, mas na hora que falaram que era um câncer 
que ele tinha, eu não acreditei... a gente pensa que isso só acontece com os outros, com a família da gente, não." (doador 6, feminino, 31 anos, casada).

Frente ao impacto do diagnóstico, a possibilidade de realização do transplante surgiu, para alguns, como um fator tranqüilizador, enquanto, para outros, parece ter funcionado como mais um desencadeador de ansiedade. Muitas vezes, os temores e fantasias acerca do procedimento estavam relacionados ao desconhecimento da técnica, uma vez que a maioria dos sujeitos nunca havia ouvido falar em transplante de medula óssea, e menos ainda em doação de medula. Em alguns depoimentos, aparece ainda a percepção das dificuldades inerentes ao procedimento, sendo mencionadas as restrições impostas por tal técnica à vida do paciente e até mesmo os óbitos decorrentes de complicações do TMO, como ilustrado a seguir.

"As pessoas, depois do TMO, sobrevivem uns seis meses, fica doente o tempo todo, né? Mas é a chance dele de viver mais algum tempo..." (doador 7, feminino, 33 anos, desquitada).

Essa ambivalência entre a confiança na possibilidade de cura e a inevitabilidade de um desfecho fatal permeou o discurso dos doadores. O potencial de salvação foi apontado como o fator mais significativo que os levou a se decidirem favoravelmente à realização do TMO.

"Quando falaram que era transplante, eu vi que a coisa era grave mesmo; sei que morre muita gente, mas é a chance de ficar bom, né?" (doador 3, feminino, 22 anos, casada).

Quanto à doação da medula, o fato de terem sido os escolhidos vinha, em geral, acompanhado por reações da ansiedade.
"Quando me falaram desse negócio de doação, eles me assustaram muito. Pra você ter uma idéia, chegou até a me dar febre. Tive até de sair do meu serviço. Fiquei apavorada" (doadora 7, feminino, 33 anos, desquitada).

Em geral, os doadores demonstraram que apreenderam as informações básicas acerca do processo. A fonte de medo verbalizada com maior freqüência foi a anestesia geral. Temiam não voltar mais do estado de torpor induzido pelo anestésico.

"E se, quando eu tiver lá dormindo, e eu dormir para sempre?" (doador 5, masculino, 28 anos, solteiro).

Emergiram, ainda, fantasias relativas às implicações decorrentes do processo de doação, tais como o temor de secar todo o sangue, transmitir características de personalidade ao receptor, ficar paralítico ou impotente após o ato da doação. Essa é uma confusão muito comum entre os leigos, que, estabelecem, por exemplo, uma equivalência entre a medula óssea e a medula espinhal.

“Esse negócio só me preocupa não andar mais; mas se é para salvar minha irmã, prefiro ficar na cadeira de rodas e ela, viva" (doador 9, masculino, 36 anos, desquitado).

Apesar desses temores, a recusa foi nula, sendo que o motivo maior que justificou a decisão de doar a medula foi a possibilidade e a conseqüente responsabilidade de salvar a vida do irmão, mesmo nos casos em que os membros da família constituída se posicionaram de modo contrário à doação. 
Eu tô muito assustada, tô com medo, mais da anestesia que eu te falei, por causa do meu problema de pressão alta. Eu tenho que pensar que eu tenho filhos, tenho família, tenho marido...e o pior é que eu nem tenho o apoio do meu marido... Por ele eu não doava, mas fazer o quê? Tem que ser eu! Então que seja! (doador 3, feminino, 22 anos, casada).

Apareceram como motivos para a aceitação do encargo da doação o constrangimento causado pela pressão da família nuclear e dos amigos bem como os preceitos religiosos, o que combina com os dados encontrados por Buckner et al. (1994) e Chang et al. (1998).

"Pensei em não doar, mas o que eu ia dizer pra minha família?...o que eu ia falar pra minha mãe? Aí os meus amigos também me aconselharam: teu irmão precisa docê...aí eu não tive escapatória" (doador 5, masculino, 28 anos, solteiro).

\section{Entrevista pós-doação}

Nas entrevistas ocorridas após a doação da medula, os participantes relataram não ter dormido na véspera da doação e descreveram sentimentos desagradáveis, tais como medo, nervosismo, ansiedade e preocupação. Essas sensações perduraram até o momento do ingresso no centro cirúrgico.

"Eu tenho horror de ficar internado, tava louco para que tudo acabasse e eu voltasse logo para casa" (doador 4, masculino, 27 anos, casado).

Relataram ter sentido um pouco de dor no dia posterior à doação; no entanto, afirmaram que a doação foi mais fácil do que imaginaram que seria. Citam como elementos que facilitaram tal processo o contato prévio com a equipe ocorrido no estágio pré-TMO e na primeira semana da internação do irmão bem como o apoio recebido desses profissionais.

"No final, a doação foi melhor que eu pensava, não vi nem senti nada" (doador 9, masculino, 36 anos, desquitado).

\section{Inventário de ansiedade traço-estado (IDATE)}

De acordo com os resultados desse instrumento, observou-se que os participantes não vivenciaram a situação de testagem como fonte desencadeadora de ansiedade (ansiedade-estado) nem apresentaram quadro de ansiedade instalado. Somente um deles obteve um escore acima da média esperada no IDATE, conforme evidencia a Tabela 1.

Tabela 1- Distribuição dos doadores de acordo com os resultados do IDATE, expresso em valores absolutos.

\begin{tabular}{|l|l|l|l|l|l|l|l|l|l|l|}
\hline Sujeito & 1 & 2 & 3 & 4 & 5 & 6 & 7 & 8 & 9 & 10 \\
\hline A-traço & 42 & 25 & 33 & 43 & 47 & 45 & 50 & 37 & 41 & 40 \\
\hline A- estado & 33 & 34 & 35 & 40 & 47 & 47 & 72 & 30 & 40 & 35 \\
\hline
\end{tabular}

Valores normativos: A-estado: homens: 41,29 ( $d p=10,53)$; mulheres: 43,54 ( $d p=10,02)$ A-traço: homens: 40,69 ( $\mathrm{dp}=10,65)$; mulheres: 45,34 $(\mathrm{dp}=9,88)$ 


\section{Inventário de sintomas de stress para adultos de Lipp (ISSL)}

De acordo com o ISSL, seis participantes encontravam-se na fase de resistência ao estresse, caracterizada por uma tentativa de adaptação à situação estressante, predominando a sensação de desgaste. Permanecendo o evento estressor, ou aparecendo outros concomitantemente, existe a possibilidade de avançarem para a fase de exaustão, já detectada em um dos doadores. Esses dados encontram-se sistematizados na Tabela 2.

Tabela 2- Distribuição dos doadores de acordo com os valores obtidos no ISSL, expressos em valores absolutos (número de sintomas de estresse) obtidos em cada fase.

\begin{tabular}{|l|l|l|l|l|l|l|l|l|l|l|}
\hline Sujeito & 1 & 2 & 3 & 4 & 5 & 6 & 7 & 8 & 9 & 10 \\
\hline A & 2 & 0 & 0 & 1 & 1 & 7 & 2 & 5 & 3 & 2 \\
\hline R & 2 & 0 & 1 & 2 & 6 & 5 & 5 & 4 & 5 & 4 \\
\hline E & 1 & 0 & 1 & 2 & 5 & 12 & 7 & 3 & 2 & 3 \\
\hline
\end{tabular}

Escores limites para as fases: alerta (A): 6; resistência (R): 3 e exaustão (E): 8.

\section{Teste das pirâmides coloridas de Pfister}

Foram analisados os seguintes índices técnicos: forma como o participante executa a tarefa, seqüência e disposição das etiquetas nos campos, a forma de colocação, os diferentes tipos de formação, a amplitude e constância da escolhas das cores e as próprias cores escolhidas. Tais índices possibilitaram obter indicadores dos funcionamentos lógico e emocional dos participantes.

Forma de colocação: a forma de colocação utilizada foi ordenada, evidenciando padrão de ordem na produção, com boa capacidade de organização lógica da tarefa.

Modos de colocação: a totalidade dos participantes utilizou o modo de colocação descendente (do vértice para a base), o que sugere uma busca de segurança interior, instabilidade e imaturidade na forma da análise lógica da realidade, embora esteja acompanhada pela colocação direta, que aponta a capacidade de respeito ao padrão lógico coletivo de nossa cultura.

Tipos de formação: observou-se predomínio da formação denominada de estrutura (58\%), sinalizadora de capacidade de elaboração lógica, adaptação e dinamismo interno.

Fórmula cromática (amplitude e constância das cores): observa-se uma amplitude afetiva que sugere ampla receptividade ao ambiente externo, com forte sensibilidade para acontecimentos afetivos. Em relação à dinâmica da personalidade, os resultados da fórmula cromática indicam personalidades estáveis ou que procuram estabilidade e adaptação. 


\section{Cores}

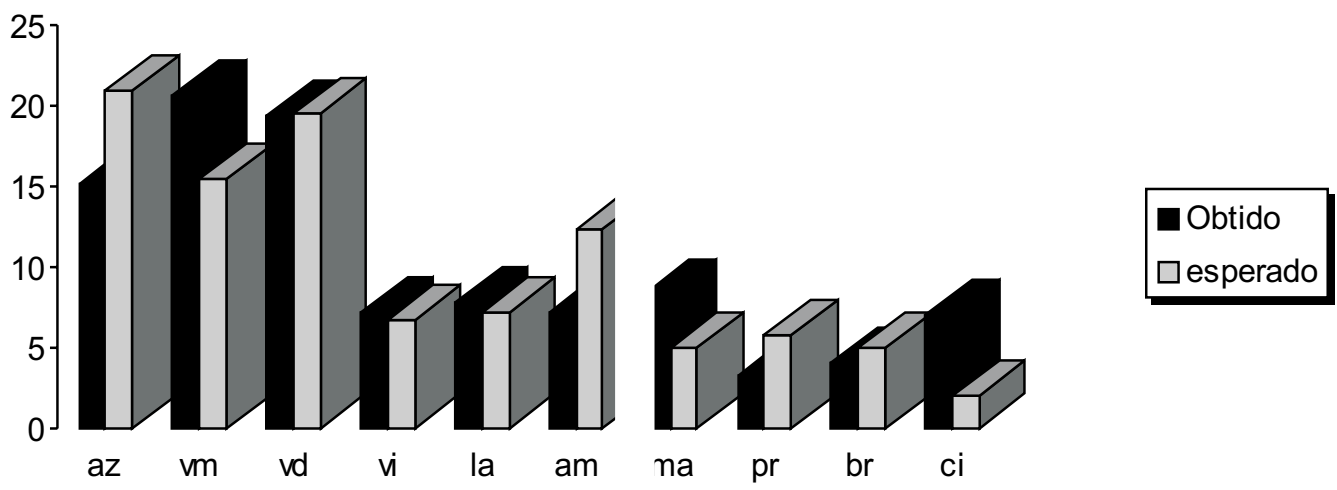

Figura 1 - Média das freqüências das cores utilizadas pelos sujeitos no teste de Pfister.

A Figura 1 evidencia o uso elevado do azul e vermelho, o que sugere dificuldade no controle racional dos afetos. Corroborando essa impressão, o amarelo rebaixado é indicativo de sugestionabilidade e inabilidade na expressão dos afetos; o cinza elevado, por sua vez, é associado à sugestionabilidade, sensibilidade e vulnerabilidade afetiva.

\section{Síndromes}

A combinação das cores possibilita o conhecimento das síndromes afetivas, representativas dos sistemas de equilíbrio interno. Em síntese, os dados sugerem que os participantes, apesar de apresentarem sinais de preservação egóica, vivenciam afetos internamente desregulados e apresentam dificuldades na expressão coordenada das vivências afetivas bem como diminuição de produtividade.

Desse modo, dentre os aspectos lógicos ou racionais analisados, encontrou-se uma evidência de padrão de ordem e capacidade de organização lógica preservada nos sujeitos, porém observouse uma diminuição da capacidade produtiva.

Em relação aos aspectos emocionais ou afetivos, tem-se uma preservação da capacidade de introversão bem como da de extroversão, com uma conservação da sensibilidade ao meio e da necessidade e estabelecimento de contatos sociais. Contudo, esses contatos são, por vezes, permeados por descargas de emoções e impulsos, que demonstram, por meio de gestos, atitudes e reações, as manifestações de ansiedade que procuram encobrir. Trata-se de indivíduos sugestionáveis, sensíveis, impressionáveis, influenciáveis, vulneráveis e dependentes, com alta suscetibilidade emocional.

\section{Desenho da família}

Primeiramente, serão analisados os aspectos relacionados aos conteúdos extraídos do inquérito e, posteriormente, as características mais salientes da produção gráfica dos participantes. 
Inquérito

Os participantes procuraram retratar, nos desenhos, as suas próprias famílias - quando casados representavam a família constituída; se solteiros, a de origem, em uma situação agradável e com sentimentos de felicidade. Tal característica denota a tentativa de negação da existência de alguém que não esteja bem ou doente no contexto familiar, uma vez que, quando questionados diretamente sobre a possibilidade de alguém estar doente ("Há alguém doente nessa família?"), todos negaram. Aparecem alguns indícios de conflitos ao relatarem o que cada familiar gosta e o que não gosta de fazer. Em relação ao futuro, este tende a ser generoso para com os personagens, que viverão juntos e felizes.

\section{Grafismo}

Aspectos gerais: A posição da folha, no momento da produção, foi a horizontal; a localização do desenho foi no $3^{\circ}$ quadrante, e o tamanho do grafismo foi médio. A localização do grafismo sugere sinais de conflitos, regressão e fixação em estágios mais primários do desenvolvimento psicoafetivo.

Aspectos formais: Tema: em palito; postura: em pé; perspectiva: frente; presença de transparências; seqüências e simetrias: normais; articulações, anatomia interna e pormenores: ausentes; certa harmonia nas proporções, correções e omissões, o que indica conflitos; tratamento diferencial em relação à idade, mas não em relação ao sexo, fato indicativo de imaturidade afetiva. Nos aspectos formais, apesar da presença de indícios de adaptação afetiva, aparecem dificuldades nas inter-relações, infantilidade, insatisfação e insegurança.
Aspectos de conteúdo: cabeça: média; cabelos: ausentes; rosto: omissão de traços fisionômicos; olhos: pequenos e em círculos; nariz: um traço só; boca: linha simples e para cima; orelha: omissão; pescoço, tronco e tórax: uma linha só; ombros, seios, cintura, cadeiras, nádegas, zona genital, abdômen: ausentes; braços e pernas: uma linha só; mãos, pés e dedos: omissão; roupas e acessórios: ausentes. Essa análise aponta a existência de dificuldades nas relações interpessoais, no contato e adaptação sociais bem como controle deficitário de impulsos, imaturidade, regressão, dependência, superficialidade e desejo de obter aprovação.

$\mathrm{Na}$ análise das produções gráficas, perceberam-se sinais de dificuldade no controle dos impulsos, associados à imaturidade, dependência, superficialidade, insatisfação, insegurança e desejo de obter aprovação e aceitação social. Esse quadro tem implicações nos relacionamentos dos doadores, e revela indícios de dificuldades nas inter-relações.

\section{Discussão}

O presente estudo procurou avaliar aspectos psicológicos dos doadores, a partir de uma ótica que combina os resultados de diversos instrumentos (inventários, entrevistas, técnicas projetivas), visando a uma compreensão mais ampla dos aspectos psicológicos envolvidos na doação da medula. Nesse momento, os resultados obtidos serão discutidos com base nos dados encontrados na literatura específica da área.

Os dados das entrevistas mostram que, na fase anterior ao processo de doação da medula óssea, uma questão primeira aparece de modo recorrente: o impacto do adoecimento de um familiar na vida desses indivíduos, que 
é desencadeador de reações descritas como "susto" e "desespero", diante de algo desconhecido, inusitado e estranho, que mobiliza toda a unidade familiar. Tal dado é corroborado pela literatura, que mostra que o impacto psicológico do diagnóstico não atinge apenas o paciente, mas toda a sua unidade familiar (Krasuska; Stanislawek, 2003).

Uma das dificuldades apontadas pelos doadores na aceitação do diagnóstico do irmão é a contradição entre o paciente "parecer bem" e "poder morrer" a qualquer momento, relacionada às peculiaridades das enfermidades de base da maioria dos pacientes, cuja sintomatologia é discreta, tanto que a maioria dos doadores não notou que havia algo errado com a saúde do irmão.

São comuns nos relatos as mudanças que ocorreram depois da descoberta da doença do irmão, em especial no sistema familiar. De acordo com Rivera (1997) e Weitzner e Kuntzer (1998), essas modificações aparecem não só acompanhadas de tonalidade emocional disfórica, dada a possibilidade de perda de um ente querido, como também positivamente, como oportunidade de aproximação familiar. Tal aproximação familiar parece estar diretamente relacionada com a sobrecarga de sentimentos mobilizados pelo diagnóstico de câncer, cujo reservado prognóstico traz consigo o temor em relação à possibilidade da perda do familiar, transformando-se em sentença de morte, apesar dos avanços técnicos obtidos nas últimas décadas. No momento da descoberta, os doadores ressaltam a importância "de diferenças serem esquecidas" e da família permanecer mais próxima, mais unida.

Aliado ao adoecimento do irmão, aparece ainda o fato de o transplante ser visto, ao mesmo tempo, como um tratamentosalvador e ameaçador (Copper; Powell, 1998), que gera importante impacto psicológico no paciente e na sua família (Krasuska; Stanislawek, 2003). Isso acontece porque ainda se trata de um procedimento que envolve alto risco de morbi-mortalidade. Em que pese o formidável desenvolvimento alcançado nos dias atuais, ainda envolve sérios riscos para o paciente, como a perda da integridade física e, acima de tudo, da própria vida (Kristjanson et al., 1998). Trata-se, porém, de uma efetiva possibilidade de salvação, muitas vezes considerada como o único meio de se alcançar a cura (Prows; McCain, 1997), e essa esperança é o que faz com os que os doadores incentivem o irmão a submeter-se ao TMO, acreditando ser esse o único meio de o paciente retomar a vida que tinha antes do diagnóstico.

Quanto à decisão da doação da medula, apesar dos medos referentes ao processo de doação, em especial ao da anestesia geral, das confusões acerca de futuras limitações (como a fantasia de ficar paralítico) e de nem todos terem ficado satisfeitos com a notícia de que seriam os doadores, a recusa da doação é nula. O fato de se insurgirem contra desejos pessoais para se submeterem às necessidades prementes do irmão também foi evidenciado nos instrumentos projetivos, nos quais aparecem indícios de sugestionabilidade, dependência e desejo de obter aprovação e aceitação social.

Esses dados corroboram os resultados encontrados da literatura, que apontam, como principais motivações, na doação relacionada, o fato de o sujeito ser colocado, potencialmente, como o salvador da vida de um membro familiar e os preceitos religiosos, sendo muito difícil a recusa em tais circunstâncias, apesar do medo e da ambivalência em relação ao desejo de doar a 
medula (Buckner; Petersen; Bolonesi; 1994; Switzer et al., 2003).

Essa responsabilidade de doar a medula e de colocar sobre si o encargo de "salvar o irmão", e a conseqüente impossibilidade de recusa da tarefa, de acordo com Shama (1998), pode tornar-se opressiva e conduzir à angústia psicológica e à ansiedade no doador relacionado de medula óssea.

Chama a atenção o fato de as manifestações de ansiedade, que aparecem de forma recorrente na entrevista, não poderem ter sido detectadas no IDATE. Uma hipótese explicativa, de acordo com os instrumentos projetivos, é que os doadores procurariam encobrir a ansiedade, que acabaria sendo expressa indiretamente por meio de atitudes, temores, somatizações e passagens ao ato, conforme pode ser ilustrada por um dos doadores (participante 7, feminino, 33 anos, desquitada), que, após ter recebido a notícia de que fora ela a escolhida, "teve febre, ficou apavorada, teve até que sair do serviço".

Apesar de ter sido detectada ausência de quadro de ansiedade instalado, aparece claramente configurado o quadro de estresse, na fase de resistência ao evento estressor, momento em que o doador ainda possui reservas energéticas. Esses dados vão ao encontro do esperado segundo a literatura, uma vez que, de acordo com Futterman e Wellisch (1990), os doadores relacionados de medula óssea apresentam reações emocionais negativas, advindas do estresse da doação. Esse estresse não pode ser completamente explicado pelo impacto físico do procedimento, mas é suscitado, em larga medida, pelos significados atribuídos ao acontecimento, modulados pelas circunstâncias delicadas que a família atravessa no TMO.

De acordo com os dados coligidos durante as entrevistas, esse quadro de estresse acaba interferindo em todas as esferas da vida do irmão-doador. Os participantes relataram dificuldades familiares e profissionais, sendo ainda detectada uma diminuição da capacidade produtiva no teste de Pfister, apesar da preservação da capacidade lógica.

Uma hipótese para a diminuição do pragmatismo seria a de que os recursos intelectuais não estariam, nesse momento, disponíveis para serem utilizados com criatividade na construção de alternativas saudáveis e de novas formas de viver, já que são canalizados para a resolução do conflito que vivenciam. Esse dado se assemelha aos dados encontrados por Almeida, Loureiro e Voltarelli (1998) nos pacientes que vivenciaram o TMO.

Em relação às dificuldades familiares, no discurso dos doadores, evidencia-se o conflito que se estabelece entre a família de origem, que incentiva e, até certo ponto, pressiona para que a doação aconteça, e a família constituída, que, muitas vezes, se opõe tenazmente a tal ato. Tais conflitos aparecem sinalizados nos desenhos da família, acompanhados de indícios de insatisfação e insegurança. A evidência de conflitos familiares deflagrados pela oportunidade de doar a medula também foi um dado encontrado por Christopher (2000).

Conforme os resultados, percebe-se que o quadro de tensão e estresse perdura até a véspera da doação, sendo que, nesse momento, figuram, como fatores tranqüilizadores, o contato prévio com o ambiente hospitalar e o fato de ficarem internados dentro da própria UTMO, com o apoio da equipe que, nessa altura, já lhe é familiar.

Cabe a essa equipe estar consciente das implicações psicológicas advindas do processo 
de doação bem como do papel essencial que desempenha na continência da dor emocional desencadeada. É perfeitamente possível amenizar esse período crítico da vida dos doadores que, apesar do momento de extrema fragilidade psíquica que manifestam, também apresentam recursos adaptativos para superarem esse desafio, tais como capacidade lógica preservada e introspecção e permeabilidade à ajuda externa, e podem se beneficiar de intervenções diretivas de apoio, contínuo suporte e esclarecimento por parte dos profissionais de saúde.

\section{Considerações finais}

A doação de medula acarreta diversas implicações psicológicas para o irmão doador, que vivencia, como eventos estressores, o adoecimento do irmão, a decisão do tratamento, a descoberta e a responsabilidade de ser o doador e o medo dos acontecimentos futuros. No período que precede a doação, o doador apresenta quadro de estresse instalado e manifestações de angústia, sintomas que comprometem várias esferas de sua vida. O processo adaptativo tende a ser restabelecido gradualmente, após o término do procedimento de aspiração da medula óssea. A possibilidade de retorno ao cotidiano familiar é vivenciada com satisfação pelo cumprimento de uma tarefa bem-sucedida, o que permite avaliar a forte carga de tensão emocional.

Frente aos resultados, é interessante que a equipe possa traçar estratégias de intervenção, tanto informativas como terapêuticas, que permitam atender as necessidades específicas desses indivíduos em cada momento (pré, durante e pós-doação), estendendo-se desde o período da descoberta de que seriam os doadores até o final do longo percurso de tratamento dos irmãos (CONTEL et al., 2000).

Érika Arantes de Oliveira

Psicóloga da Unidade de Transplante de Medula Óssea (UTMO) do HCFMRP-USP e do Departamento de Psicologia e Educação da FFCLRP. Doutora em Ciências pelo Programa de Pós-Graduação da FFCLRP-USP

Faculdade de Filosofia, Ciências e Letras de Ribeirão Preto-USP

Hospital das Clínicas da Faculdade de Medicina de Ribeirão Preto

Rua Machado de Assis, 433

Vila Tibério-Ribeirão Preto. CEP: 14050-490

E-mail: erikaao@ffclrp.usp.br

\section{Manoel Antônio dos Santos}

Psicólogo, Doutor, prof. do Curso de Psicologia do Departamento de Psicologia e Educação da FFCLRP-USP Faculdade de Filosofia, Ciências e Letras de Ribeirão Preto-USP

\section{Ana Paula Mastropietro}

Terapeuta ocupacional da UTMO do HCFMRP-USP e docente do Curso de Terapia Ocupacional das Faculdades Claretianas de Batatais, Hospital das Clínicas da Faculdade de Medicina de Ribeirão Preto

\section{Júlio César Voltarelli}

Médico coordenador da UTMO do HCFMRP-USP. Doutor, prof. do Curso de Medicina da FMRP-USP Faculdade de Medicina de Ribeirão Preto-USP. Hospital das Clínicas da Faculdade de Medicina de Ribeirão Preto

Recebido 16/08/06 Reformulado 18/12/06 Aprovado 25/01/07 
ALMEIDA, A. C.; LOUREIRO, S. R.; VOLTARELLI, J. C. O ajustamento social e qualidade de vida de pacientes submetidos ao transplante de medula óssea. Medicina Ribeirão Preto, v. 31, p.296-304, 1998.

ANDRYKOWSKI, M.A. Psychiatric and psychosocial aspects of bone marrow transplantation. Psychosomatics, New York, v. 35, no 1, p. 13-24, 1994.

BIAGGIO, A.; NATALICIO, L. F.; SPIELBERGER, C. D. Desenvolvimento da forma experimental em português do IDATE. Arquivos Brasileiros de Psicologia Aplicada, Rio de Janeiro, v. 29, p. 33-44, 1977.

BOGDAN, R.; BIKLEN, S. Investigação qualitativa em educação: uma introdução à teoria e aos métodos. Portugal: Porto Editora 1991.

BREDESON, C.; LEGER, C.; COUBAN, S.; SIMPSON, D.; HUEBSCH L.; WALKER, I.; SHORE, T.; HOWSON-JAN, K.; PANZARELLA, T.; MESSNER, H.; BARNETT, M.; LIPTON, J. An evaluation of the donor experience in the Canadian multicenter randomized trial of bone marrow versus periphel blood allografting. Biological Blood Marrow Transplantation, Charlottesville, v. 10, no 6, p.405-414, 2004.

BREWER, J.; HUNTER, A. Multimethod research: a synthesis of styles. Califórnia, Sage: Newbury Park, 1989.

BUCKNER, C. D., PETERSEN, F. B.; BOLONESI, B. A. Bone marrow donors. In: FORMAS, S. J.; BLUME, K. G.;THOMAS, E. D. (Eds.), Bone marrow transplantation, Boston, 1994. p. 259-265.

CHANG, G.; MCGARIGLE, C.; SPITZER, T. R.; MCAFEE, S. L.; HARRIS F.; PIERCY, K.; GOETZ, M. N.; ANTIN, J. H. A comparison of related and unrelated marrows donors. Psychosomatic Medicine, Baltimore, v. 60, no 2, p.163-167, Mar.-Apr. 1998

CHANG, G.; MCGARIGLE, C.; KOBY, D; ANTIN, J. Symptoms of pain and depression in related marrow donors: chances after transplant. Psychosomatics, New York, v. 44, no 1, p. 59-64, Jan.-Feb. 2003.

COOPER, M. C.; POWELL, G. Technology and care in a bone marrow transplantation unit: creating and assuaging vulnerability. Holistic Nursing Practice, v. 12, no 4, p. 57-62, jul., 1998.

CONTEL, J. O. B.; SPONHOLZ Jr, A.; TORRANO-MASETTI, L. M. ALMEIDA, A. C.; OLIVEIRA, E. A.; JESUS, J. S.; SANTOS, M. A.; LOUREIRO, S. R.; VOLTARELLI, J.C. Aspectos psicológicos e psiquiátricos do transplante de medula óssea. Medicina Ribeirão Preto, v.33, p. 294-311, 2000.

CORMAN, L. O teste do desenho de família. Trad. Walter $\mathrm{H}$. Geenen. São Paulo: Mestre Jou, 1994.

CHRISTOPHER, K.A. The experience of donating bone marrow to a relative. Oncology Nursing Forum, New York, v. 27, p. 693-700, 2000.

CUNHA, J. A. (Org). Psicodiagnóstico-V. Porto Alegre: Artes Médicas, 2000

DEMKO, S. G. Transplantation procedures. In: BURT, R. K.; DEEG, H. J.; LOTHIAN, S. T.; SANTOS, G. W. (Eds.). Bone marrow transplantation. Georgetown: R.G. Lands Company, 1998. p. 3950.

DIERS, B. D. Research in nursing practice. Philadelphia: J.B. Lippincott, 1978.

FORTANEIR, C.; KUENTZ, M.; SUTTON, L.; MICHAEL, M.; MACQUART-MONNIN, G.; FAUC'HER, C.; Le CÓRROLLER, A. G. MOATRI, J. P.; BLAISE, D. Healthy sibling donor anxiety and pain during bone marrow or peripheral blood stem cell harvesting for allogeneic transplantation: results of a randomized study. Bone marrow transplantation, London, v.29, no 2, p.145-149, 2002.

FUTTERMAN, A. D; WELLISCH, D. K. Psychodynamic themes of bone marrow transplantation. Hematological oncological clinic North American, Philadelphia, v. 4, p. 699-709, 1990.

KRASUSKA, M.E; STANISLAWEK, A. Communication with patients and their families, who undergo bone marrow transplantation. Annales universitatis Mariae Curie Sklodowska, Lublin, v. 58, n2, p. 168-73, 2003

KRISTJANSON, L. J.; NIKOLETTI, S.; POROCK, D.; SMITH, M; LOBCHUK, M; PEDLER, P. Congruence between patients and family caregiver's perceptions of symptom distress in patients with terminal cancer. Journal of Palliative Care, Toronto, v. 14, no 3, p. 24-32, 1998.

LESKO, L. M. Bone marrow transplantation. In: HOLLAND, J.; ROWLAND, J. (Eds.) Handbook of Psychooncology-psychological Care for the Patient with Cancer. New York: Oxford University Press, 1990, p.163-172.

LIPP, M. E. N.; GUEVARA, A. J. Validação empírica do inventário de sintomas de stress (ISS). Estudos de Psicologia, Campinas, v. 3-4, p. 6-19, 1984.

LIPP, M. E. N.; ROCHA, J. C. Stress, hipertensão arterial e qualidade de vida. Campinas-SP: Papirus, 1994.

LIPP, M.E.N. Manual do Inventário de Sintomas de Stress para Adultos de Lipp (ISSL). São Paulo: Casa do Psicólogo, 2000.

LOURENÇÃO VAN KOLK, O. Testes projetivos gráficos no diagnóstico psicológico. São Paulo: EPU, 1984.

MARQUES, M. O teste das pirâmides coloridas de Max Pfister. São Paulo. EPU/EDUC, 1988

MINAYO, M. C. S. O desafio do conhecimento: pesquisa qualitativa em saúde. São Paulo - Rio de Janeiro: Hucitec - Abrasco, 1994.

PROWS, C.: MCCAIN, G. Parental consent for bone marrow transplantation in the case of genetic disorders. Journal of the Society of Pediatric Nurses, Philadelphia, v. 2, no 1, p. 09-18, Sep. 1997.

RIVERA, L. M. Blood cell transplantation: its impact on one family. Seminars Oncology Nursing, Orlando, v. 13, no 3, p. 194-199, Aug. 1997.

ROLLAND, J.S. Ajudando as famílias com perdas antecipadas. In: WALSH, F.; MCGOLDRICK, M. Morte na família: sobrevivendo às perdas. Dornelles, C. O., trad. Porto Alegre: ArtMed, 1998, p. 166186

SANTOS, M. A. Desenho da família: método de análise. Mimeografado, Ribeirão Preto, 1997.

SHAMA, W. I. The experience and preparation of pediatric sibling bone marrow donors. Social Work in Health Care, New York, v. 27, no 1, p. 89-95, 1998.

SPIELBERGER, C. D., GORSUCH L. R.; LUSHENE R. E. Manual do Inventário de Ansiedade Traço-Estado Manual. Biaggio, A., trad. Rio de Janeiro: CEPA, 1979.

STRONCEK, D. F., HOLLAND; P. V.; BARTCH, G. Experience of the first 493 unrelated marrow donors in the National Marrow Donor Program. Blood, New York, v. 81, p.1940-1946, 1993.

SWITZER, G.E.; MYASKOVSKY, L.; GOYCOOLEA, J. M.; DEW, M. A.; CONFER, D. L.; KING, R. Factors associated with ambivalence about bone marrow donation among newly recruited unrelated potential donors. Transplantation, Baltimore, v.75, no 9, p. 1517-1523, 2003.

THOMAS, E.D. Transplante de medula óssea: uma revisão histórica. Medicina Ribeirão Preto, Ribeirão Preto, v. 33, p.209-218, 2000.

TRIVIÑOS, A. N. S. Introdução à pesquisa em ciências sociais: a pesquisa qualitativa em educação. São Paulo: Atlas, 1992.

VILLEMOR AMARAL, F. Pirâmides coloridas de Pfister. Rio de Janeiro: CEPA, 1978.

WEITZNER, M. A.; KNUTZER, R. The impact of pituitary disease on the family caregiver and overall family functioning. Psychotherapy and Psychosomatics, Basel, v. 67, no 3, p. 181-188, 1998.

WOLCOTT, D. L.; WELISCH, D. K.; FAWZY, F. I.; LANDSVERK, J. Psychological adjustment of adult bone marrow transplant donors whose recipient survivors. Transplantation, Baltimore, $v .41, \mathrm{n}=4, \mathrm{p}$. 484-488, 1986

WILLIAMS, L. A; MCCARTHY, P. L. Patients and donor evaluation. In: BURT, R.K.; DEEG, H.J.; LOTHIAN, S.T.; SANTOS, G.W. (Eds). Bone marrow transplantation. Georgetown: R.G. Lands Company, 1998. p. 14-21.

\section{Referências}

